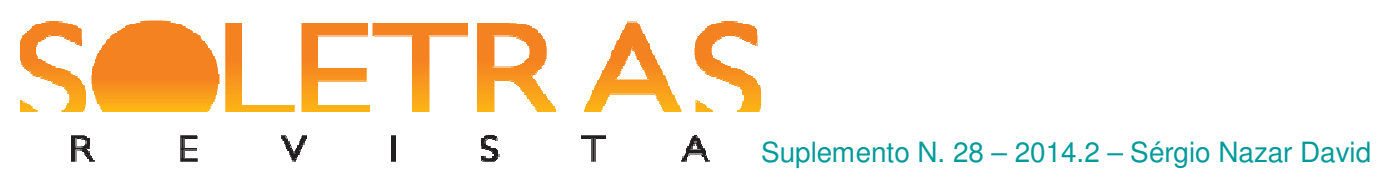

\title{
Garrett e os livros: a presença dos clássicos na biblioteca do Conservatório Real de Lisboa
}

\author{
Sérgio Nazar David ${ }^{1}$
}

Universidade do Estado do Rio de Janeiro

\begin{abstract}
Resumo: A posição de Garrett à frente do Conservatório Real de Lisboa, da Inspecção Geral de Teatros, também como membro da comissão para a edificação do Teatro Dona Maria II foi inegavelmente de defesa dos clássicos. Bem o comprovam a listagem dos livros que solicitou que fossem recolhidos das bibliotecas dos extintos conventos para o Conservatório, e também a listagem de doações que o Conservatório recebeu. Mas não só. O protagonismo que Garrett teve na cena teatral portuguesa após o retorno da Bélgica em 1836 tem a ver com a sua proximidade com Passos Manuel e com Rodrigo da Fonseca Magalhães. Para a cena política, Garrett não era capaz de compreender qualquer avanço sem o equilíbrio entre passado e presente. O papel de Garrett na construção do Teatro D. Maria II e na organização do Conservatório Dramático está em consonância com a ideia, defendida em vários pontos de sua obra, de relação dialética entre o clássico e o romântico.
\end{abstract}

Palavras-chave: Garrett. Conservatório Real de Lisboa. Clássicos.

\section{I}

A presença da cultura clássica em Garrett tem o seu marco primeiro na formação que recebeu do tio paterno, poeta árcade e bispo de Angra do Heró́smo, D. Frei Alexandre da Sagrada Família (1737-1818) no período em que viveu na ilha Terceira (1809 a 1816). Dois outros mestres também colaboraram na formação do jovem João Baptista: o tio materno, João Carlos Leitão; e o professor de retórica e poética, Joaquim Alves².

Depois veio a passagem pela Universidade de Coimbra (de 1816 a 1821), sobretudo na camaradagem intelectual, no teatro acadêmico e no convívio nas lojas maçónicas, que certamente imprimiram suas marcas classicizantes no jovem estudante de Leis.

\footnotetext{
${ }^{1}$ Sérgio Nazar David é professor associado da UERJ, bolsista de Produtividade em Pesquisa do CNPq, membro da Associação Portuguesa de Escritores e da "Equipe Garrett" (Centro de Literatura Portuguesa - Faculdade de Letras - Coimbra). É autor de: Onde moedas de chumbo (poesia, RJ, 7Letras, 2001; 2. ed. 2014), Freud e a religião (ensaio, RJ, Zahar, 2003), A primeira pedra (poesia, RJ, 7Letras, 2006; 2. ed., 2014), O século de Silvestre da Silva (ensaio, 2 vols., Lisboa, Prefácio / RJ, 7Letras, 2007) e Tercetos queimados (poesia, RJ, 7Letras, 2014). Organizou as edições críticas de Cartas de amor à Viscondessa da Luz (Famalicão, Edições Quasi, 2007) e de Correspondência familiar (Lisboa, Imprensa Nacional; Casa da Moeda, 2012), de Almeida Garrett. E-mail: snazardavid@gmail.com.

${ }^{2}$ Ver Amorim, tomo I, 1881, p. 90; Monteiro, 1971, vol. I, p. 81; e também Morão, 2012, p. 106.
} 


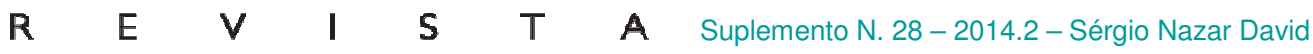

Os poemas da Lírica de João Mínimo - todos datados de 1815 a 1824, recolhidos em volume em 1829 (segundo Amorim, Garrett "punha datas ao acaso"3 ${ }^{\text {) }}$-; o poema $O$ retrato de Vénus (1821); e o Catão (1822) serão alguns frutos provenientes do diálogo que o escritor travou com a cultura clássica no tempo que Ofélia Paiva Monteiro chamou "período de formação", , da infância ao retorno da Bélgica em 1836. A Grécia faz-se presente na formação de Garrett, através da busca da liberdade, sobretudo no campo político e dos afetos ${ }^{5}$.

Fixemos por ora uma anotação mais do que conhecida: a passagem de Garrett pelas formas e motivos clássicos era e continuará, nos anos subsequentes, sendo um modo eficaz de chegar aos impasses maiores de seu tempo e de seu país. Do prefácio da $3^{\mathrm{a}}$ edição do Catão, cito: “[...] fui a Roma; fui, e me fiz romano quanto pude, segundo o ditado manda: mas voltei para Portugal, e pensei de português para portugueses: e a isso atribuo a indulgência e boa vontade do público [...]". 6

O diálogo e a tensão entre o clássico (mais universal) e o romântico (mais particular) dão as bases da extraordinária coerência do homem público e do escritor em direção às obrasprimas fundamentais da maturidade: Frei Luís de Sousa (1843-1844), Viagens na minha terra (1843-1845-1846) e Folhas caídas (1853). Ainda do prefácio à terceira edição do Catão, destacamos:

Essas guerras de 'alecrim e manjerona' em que andaram clássicos e românticos [...] vão a começar por cá. E como na política e em tudo, não se aprende nos exemplos, nos erros alheios: triste condição da Humanidade que só de seus próprios desvarios escarmenta cada um! Paciência! Quanto a isso, só quero aqui reiterar os meus antigos protestos de que não sou clássico nem romântico: porquê? Porque tratei de saber o que era uma coisa e o que era a outra antes de me apaixonar por nenhuma. Sucedeu-me o que me tem sucedido em tudo [...]: achei razão a uns e a outros, segui-os nela, e deixei-os brigar no mais [...]. Assim é de tantas brigas deste mundo! ${ }^{7}$

Na "Nota bene" (de 1839), apensa ao prefácio à 1ª edição de Catão (de 1822), Garret registra:

Os fundamentos das minhas opiniões literárias, ver-se-á que eram os mesmos há dezoito anos; desenvolveram-se, rectificaram-se, mas não mudaram. Mal, e como de criança, aí vem, contudo, já pressentida a ideia de Goethe na última parte do FAUSTO, sobre a combinação do clássico com o romântico que deve produzir e fixar a poesia moderna ${ }^{8}$.

\footnotetext{
${ }^{3}$ Amorim, tomo I, 1881, p. 162.

${ }^{4}$ Monteiro, 1971. 2 vols.

${ }^{5}$ Ver Jabouille, 1997, pp. 111-117.

${ }^{6}$ Garrett, 1963, vol. II, p. 1618.

${ }^{7}$ Garrett, 1963, vol. II, p. 1619.

${ }^{8}$ Garrett, 1963, vol. II, p. 1612.
} 
Uma vez mais, no prefácio à terceira edição do Catão, vemos, na passagem que se segue, os fortes laços que ligavam Garrett ao pai e ao tio:

[...] as minhas opiniões, os meus sentimentos, as minhas simpatias como homem, como cidadão, como filósofo tal qual, como cristão verdadeiro e sincero, não variaram desde que me conheço, - espero amortalhar-me nelas. Umas me entraram no primeiro sangue com o leite que mamei dos peitos de minha virtuosa e extremosa mãe: outras se me esculpiram no cérebro mole com a educação liberal, mas rígida e severa, em que fui duramente moldado desde a infância, por meu pai, um dos homens mais honrados e austeros que ainda houve nesta terra, - por um tio, filólogo, sábio e erudito daqueles que já não há e que Deus sabe quando tornará a haver em Portugal. ${ }^{9}$

Se está certo que o romantismo é, sob muitos aspectos, o liberalismo na literatura, podemos então, neste tópico, concluir que João Baptista recebeu do tio o classicismo (não um classicismo rígido, formalista e estéril ${ }^{10}$ ); do pai lhe veio o romantismo. A síntese ficaria por sua conta e risco.

\section{II}

O período que se segue à chegada de Garrett da Bélgica em 1836 é dos mais fecundos. Como já assinalou Ofélia Paiva Monteiro, é um momento, não de ruptura, mas de aprofundamento e maturação em todos sentidos.

O homem que chega a Lisboa sabe que a sua nomeação para a Bélgica atendera a sórdidas conveniências políticas (fora na verdade afastado do país pelos amigos de D. Pedro); vem marcado por dois anos de penúria - comprovada pela correspondência diplomática do período - em Bruxelas; além disso, a sua substituição no posto de Encarregado de Negócios na capital belga fora vergonhosa; e por fim dera-se, havia pouco, a separação de Luísa Cândida Midosi, com quem se unira em 8/11/1822, na Igreja de São Nicolau, pelas mãos do padre José Narciso Pereira de Carvalho e Araújo, maçom assumido e membro da Sociedade Literária Patriótica.

Há elementos contundentes para afirmarmos que, aos 37 anos, Garrett traz na bagagem de viajante algo mais que a desesperança. Os reveses, já vividos e outros que se seguirão, farão do autor de Camões e D. Branca cada vez mais um exilado em sua própria terra. Sempre muito independente, ainda assim nunca deixa de pugnar pelos caminhos possíveis na esfera

\footnotetext{
${ }^{9}$ Garrett, 1963, vol. II, p. 1617.

${ }^{10}$ Monteiro, 1974, pp. 185-235.
} 
dos assuntos públicos, consideradas as circunstâncias, os vetores em conflito e os objetivos que desenha no horizonte.

Garrett, ao chegar a Lisboa, elege-se deputado já em 1837. De sua atividade nos anos seguintes destaque-se a defesa dos católicos do Porto.

Fixemos o trecho do discurso proferido em 1/7/1839:

[...] sou eu defensor da causa religiosa, sou eu o que quero pugnar pelos pretendidos cismáticos e que os hei-de defender enquanto me não tirarem a cabeça e ma levarem esse pseudo-liberais na ponta das baionetas; hei-de defender [...] a causa da liberdade religiosa, sempre, porque ela é a base de toda a liberdade, daquela por que tenho sacrificado toda a minha saúde, vida e pequena fortuna, porque não creio que possa haver liberdade civil para o povo que perder a liberdade religiosa. ${ }^{11}$

Em carta ao irmão, Alexandre José, de 9/9/1839, registra:

O Liberalismo falso que receia o Catolicismo - os falsos católicos que recusam a liberdade [...] ambos pecam contra Jesus-Cristo e contra a sua lei. - Ao menos este é o meu credo e nele hei-de morrer. - Mas por ora não disse ainda tudo isto na tribuna, e ardo pelo dizer. ${ }^{12}$

A posição de Garrett em relação ao cisma religioso tem eco nas Viagens na minha terra. Quando narra o traslado dos ossos de S. Frei Gil do convento de São Francisco para o das Claras - no ano de 1834 - o nosso Autor comenta: "Entremos nesse convento das pobres Claras, tão aflitas e desconsoladas agora que as ameaçam de dissolução como aos frades".13 Frei Dinis é um dos religiosos que participa do traslado: carregam durante a noite "uma espécie de cofre" na esperança de que nas Claras - uma ordem feminina - estarão mais adequadamente resguardadas as relíquias. Ainda assim o temor é grande de que a perseguição recaísse igualmente sobre todas as ordens. "Não será assim", comenta o Autor, pois "aquelas instituições não metem medo aos verdadeiros liberais, e os outros lá tem o espólio dos frades para devorar $[\ldots] " .{ }^{14}$

A crítica aos devoristas (os amigos de D. Pedro) está posta. Citamos dois exemplos (a nomeação para a Bélgica e as posições em relação aos chamados cismáticos) do quanto a distância de Garrett em relação aos cartistas sempre esteve marcada. Do mesmo modo, a história de lutas, desde os tempos de estudante de Coimbra, contra o despotismo, permite-nos asseverar que os seus discursos em prol da liberdade religiosa, no final dos anos 30,

\footnotetext{
${ }^{11}$ Apud Amorim, tomo II, 1884, p. 512.

${ }^{12}$ Garrett, 2012, pp. 188-189.

${ }^{13}$ Garrett, 2010, p. 396.

${ }^{14}$ Garrett, 2010, p. 396, grifo nosso.
} 


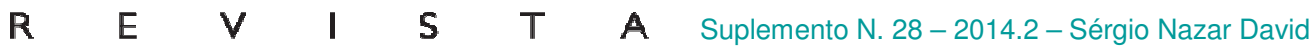

certamente não o tornaram mais confiável à facção miguelista. Mais: aos chamados "democratas" (setembristas), recorde-se que a crítica de Garrett foi também severa. Temia muito a manipulação das massas iletradas e despolitizadas. As cenas de multidão d' $O$ Arco de Sant'Ana nos trazem, em justíssima medida, a posição de suspeita - permitam-me - do nosso Alceu em relação ao clero (representado ali pelo Bispo do Porto), em relação aos representantes do povo, mas também ao próprio povo, tão facilmente ludibriado. Resumindo: miguelismo, cartismo, cabralismo, a todos Garrett teceu críticas e buscou ultrapassar, não com o ceticismo ou o cinismo, mas com a "broca da análise", se recordamos a lição de Mouzinho da Silveira.

\section{III}

A carta de Manuel da Silva Passos (Passos Manuel) à Rainha D. Maria II rogando o amparo ao teatro português começa lembrando o lugar que o dramaturgo tivera na corte de D. Manuel I:

O mesmo genio poderoso que mandava descobrir a Índia, e que alterava o modo de existir do universo, mandou também abrir a scena moderna da Europa. E o senhor rei D. Manuel tanto achou em Portugal os animos e os corações de Vasco da Gama e de Pedro Nunes como os talentos d'este e os de Gil Vicente ${ }^{15}$.

A Rainha aprovou a proposta de criação do Conservatório e da Inspecção Geral de Teatros em 15/11/1836. Garrett é nomeado Inspector Geral de Teatros em 22/11/1836 ${ }^{16}$. Em 24/11/1838, Garrett escreve à Rainha, "fala com enthusiasmo do nascente estabelecimento, dizendo que d'elle espera a regeneração do theatro portuguez". Elogia as diligências do ministro "zeloso e patriota" (Passos Manuel) que o tinha alçado à testa do empreendimento. $\mathrm{O}$ líder setembrista já não respondia pelo Ministério do Reino desde 31/5/1837. Exalta “o poderoso meio de civilização" que é o teatro e encaminha 65 artigos, que compõem o REGIMENTO, que afinal, em 27/3/1839, a Rainha e António Fernandes Coelho (Ministro do Reino) assinam ${ }^{17}$.

Por decreto de 4/7/1840, o Conservatório Geral de Arte Dramática passa a chamar-se Conservatório Real de Lisboa.

\footnotetext{
${ }^{15}$ Apud Amorim, tomo II, 1884, pp. 247-248.

${ }^{16}$ Ribeiro, 1876, tomo VI, p. 393.

17 Carta de 24/11/1838 de Garrett à Rainha D. Maria II e "Regimento" do Conservatório Geral de Arte Dramática. DGARQ/TT, Ministério do Reino, $4^{\mathrm{a}}$ repartição, Instrução Pública, Negócios Diversos, Conservatório Real de Lisboa, 1835-1843, Mç. 2127.
} 
A correspondência de Garrett para Rodrigo da Fonseca Magalhães, Ministro do Reino em 1841, evidencia o empenho do Vice-Presidente do Conservatório (o Presidente era D. Fernando) pela aprovação dos ESTATUTOS. Em carta de 15/3/1841, Garrett reclama do amigo Rodrigo uma posição, mesmo que negativa, em relação à aprovação dos ESTATUTOS: “[...] ninguém accreditará em Portugal que ha meses eu tenha falado a V. Ex ${ }^{\mathrm{a}}$. mais de seis vezes n'este grande negocio, escripto não sei quantos de officio, não sei quantas oficiosamente, e sem resultado sempre". ${ }^{18}$ Em 31/3/1841: "Rogo a V. Ex ${ }^{a}$. com o maior empenho que se não demore a resolução d'este negocio que tanto trabalho me deu (...)"19. Pede, por fim, em 5/4/1841, ainda em relação aos ESTATUTOS: “antes m'o reprovem do que me alterem as palavras, virgulação ou orthographia; e que se houver dúvida em alguma cousa na secretaria, me mandem chamar para se arranjar, ouvido eu". ${ }^{20}$

Em 24/5/1841, a Rainha e Rodrigo da Fonseca Magalhães (Ministro do Reino) vão assinar os ESTATUTOS, compostos de 109 artigos, mais 3 artigos transitórios. O depoimento de Gomes de Amorim deixa claro que ambos, REGIMENTO e ESTATUTOS, saíram da pena de ouro de Garrett. ${ }^{21}$

O REGIMENTO trata da organização e do dia a dia das três escolas que compunham o Conservatório: a de declamação; a de música, e a de dança e mímica. Exemplos: admissão de alunos, formação da biblioteca, matrículas e folhas de pagamento, composição do corpo de membros do Conservatório, elenco de disciplinas, deveres do Inspector Geral de Teatros, obrigações dos alunos, normas para que os alunos possam "debutar em um teatro", normas para jubilações, aposentações e reformas.

Os ESTATUTOS fixam princípios mais gerais: o objetivo do Conservatório, os meios para atingi-lo, a formação das comissões e classes de sócios, a admissão dos sócios (efetivos ou correspondentes), a escolha do Presidente e do Vice-Presidente, a construção do teatro do Conservatório (para os exercícios públicos dos alunos), as condições para a reforma dos ESTATUTOS.

\footnotetext{
${ }^{18}$ Carta de 15/3/1841 de Garrett a Rodrigo da Fonseca Magalhães, DGARQ/TT, Ministério do Reino, $4^{\text {a }}$ repartição, Instrução Pública, Negócios Diversos, Conservatório Real de Lisboa, 1835-1843, Mç. 2127.

${ }^{19}$ Carta de 31/3/1841 de Garrett a Rodrigo da Fonseca Magalhães, DGARQ/TT, Ministério do Reino, $4^{\mathrm{a}}$ repartição, Instrução Pública, Negócios Diversos, Conservatório Real de Lisboa, 1835-1843, Mç. 2127.

${ }_{20}$ Carta de 5/4/1841 de Garrett a Rodrigo da Fonseca Magalhães, DGARQ/TT, Ministério do Reino, $4^{\mathrm{a}}$ repartição, Instrução Pública, Negócios Diversos, Conservatório Real de Lisboa, 1835-1843, Mç. 2127.

21 "Estatutos" do Conservatório Geral de Arte Dramática. DGARQ/TT, Ministério do Reino, 4. repartição, Instrução Pública, Negócios Diversos, Conservatório Real de Lisboa, 1835-1843, Mç. 2127.
} 
Da leitura dos documentos elencados acima, gostaria de destacar ainda três pontos: a) a ideia de civilização associada à corte de D. Manuel I e a Gil Vicente; a Vice-Presidência, que coube a Garrett por eleição (sendo "um Príncipe da Real Familia" o Presidente, escolha que recaiu sobre D. Fernando); e a constituição da biblioteca do Conservatório.

No apelo à Rainha para que apoiasse o teatro português, Passos Manuel evoca a corte de D. Manuel I e Gil Vicente. Também, quando escreve uma peça de teatro - Um Auto de Gil Vicente (1838) - para impulsionar a arte dramática em Portugal, na sequência da fundação do Conservatório, Garrett escolhe o ambiente de liberdade do período manuelino. A peça recria a encenação de Cortes de Júpiter (de Gil Vicente), no momento da partida da Infanta D. Beatriz, Duquesa de Saboia. Não há como não recordar a cena de Hamlet em que uma trupe de atores encena o assassinato do pai com o intuito de surpreender o tio e desmontar uma farsa inominável. Na peça de Garrett, Bernardim Ribeiro faz o papel da moura, em Cortes de Júpiter, para com isto se aproximar da Infanta D. Beatriz, já casada, que ele tanto ama. Mas os seus subterfúgios nada conseguem no sentido de alterar o rumo dos acontecimentos. Bernardim se atira ao mar e a Infanta segue no galeão já casada com o Duque de Saboia.

A peça de Garrett insiste sobre o baixo valor social de atores e atrizes, e sobre a liberdade que deveria reger as escolhas no campo dos afetos. O mesmo Bernardim Ribeiro, personagem da peça, que se refere a D. Manuel como "[...] um príncipe que sabe a valia das artes, que estima e cultiva as letras..."22, será vítima de um mundo com pouca mobilidade social e com menos liberdade do que se supõe. Garrett tem os pés bem fincados no século XIX. Ao ambientar sua peça na corte manuelina está na verdade questionando os limites da democracia liberal oitocentista. Esta é a "pedra lançada no edifício do nosso teatro",23, afirma na "Introdução" que escreveu para a edição em volume, em 1841, de Um Auto de Gil Vicente. O teatro deve ser um poderoso veículo de civilização dentro da sociedade liberal - assim advoga Garrett em inúmeros paratextos apensos às suas obras -, mas aqui, em Um auto de Gil Vicente, não é capaz de transformá-la. Permanece sendo um ofício de diletantes.

A Vice-Presidência que coube a Garrett, no momento da criação do Conservatório, está associada à eleição de "um Príncipe da Real Família" para a Presidência. O Conservatório escolhe, entre os sócios efetivos, três nomes, que são então levadas à Rainha, para que ela escolha o Vice-Presidente. Mas é o Conservatório quem escolhe - sem lista tríplice - o Presidente. Este foi o modo encontrado por Garrett para reproduzir, na estrutura do

\footnotetext{
${ }^{22}$ Garrett, 2011, p. 69.

${ }^{23}$ Garrett, 2011, p. 15.
} 


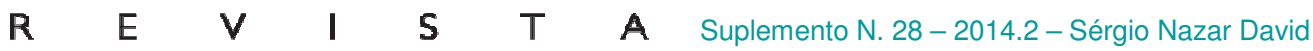

Conservatório, o modelo que tanto apreciava, que conjugava o princípio democrático com a monarquia.

Com relação à constituição da biblioteca do Conservatório, observe-se que, já em 29/4/1837,

[...] ordenou o governo que o Inspector Geral dos Theatros lhe remetesse uma relação dos livros necessários para a organização de uma livraria própria e adaptada ao serviço do Conservatorio de Arte Dramatica (...) a fim de serem escolhidos no depósito das livrarias dos extintos conventos". ${ }^{4}$

Em 27/3/1840, Garrett, referindo-se ao tal depósito, registra em carta a Rodrigo da Fonseca Magalhães:

[...] ninguém póde adivinhar o que ha n'aquelle cahos assim chamado. E já que é vontade de Sua Magestade que este indispensável auxilio me seja concedido, digne-se V. Ex ${ }^{\mathrm{a}}$. auctorizar-me a ir escolher eu mesmo entre o que poder descobrir, para me ser entregue com as ressalvas e cautelas que por utilidade publica, e não menos minha, são necessárias. ${ }^{25}$

Há três listagens de livros que, juntas, dão uma ideia do que foi a biblioteca do Conservatório. Uma delas foi elaborada pelo bibliotecário do Conservatório, Francisco Pedro da Costa Araújo, em 22/10/1841, logo depois da exoneração de Garrett da Vice-Presidência. No cabeçalho podemos ler: "Relação dos livros, impressos e manuscriptos existentes na Bibliotheca do Conservatorio Real de Lisboa". Esta listagem mostra-nos a biblioteca que Garrett conseguiu formar para o Conservatório.

Garrett é o principal doador dos livros que vão constituir tal acervo. De um total de 324 títulos, doou 60 (19\%). Dos depósitos das livrarias dos extintos conventos vieram 47 (14\%). Adquiridos pelo Conservatório foram 71 títulos (22\%). Os demais itens vieram por doações de outros sócios ou de terceiros. A soma dos livros que Garrett doou com os livros que vieram dos depósitos das livrarias dos extintos conventos, mais os que foram adquiridos no período em que esteve na Vice-Presidência, perfaz um total de 176 livros (mais de 50\% da biblioteca). Mais de metade da biblioteca do Conservatório Real de Lisboa formou-se sob os auspícios de Garrett. Nesta metade (176 livros) têm uma presença muito forte os clássicos gregos e latinos, mas figura ali também uma abertura enorme para as obras escritas nas línguas europeias modernas, o que está perfeitamente de acordo com o que vimos expondo. Trata-se do equilíbrio uma vez mais entre o clássico e o romântico, da abertura de Garrett ao

\footnotetext{
${ }^{24}$ Ribeiro, 1876, tomo VI, p. 396.

${ }^{25}$ Carta de 27/3/1840 de Garrett a Rodrigo da Fonseca Magalhães, DGARQ/TT, Ministério do Reino, $4^{\mathrm{a}}$ repartição, Instrução Pública, Negócios Diversos, Conservatório Real de Lisboa, 1835-1843, Mç. 2127.
} 


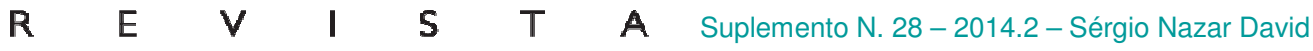

novo, ao moderno, sem prejuízo da tradição. Recordemos o prefácio não assinado de Viagens na minha terra, sabidamente de autoria de Garrett, publicado originalmente na Revista Universal Lisbonense, em 1845, no qual Garrett traça um perfil - convenhamos - nada modesto de si:

[...] o autor de Viagens na minha terra é igualmente familiar com Homero e com Dante, com Platão e com Rousseau, com Tucídides e com Thiers, com Guizot e com Xenofonte, com Horácio e com Lamartine, com Shakespeare e com Eurípedes, com Camões e Calderon, com Goethe e Virgílio, Schiller e Sá de Miranda, Sterne e Cervantes, Fénelon e Vieira, Rabelais e Gil Vicente, Addison e Bayle, Kant e Voltaire, Herder e Smith, Bentham e Cormenin, com os Enciclopedistas e com os Santos Padres, com a Bíblia e com as tradições sânscritas, com tudo o que a arte enfim e a ciência moderna têm produzido". ${ }^{26}$

É este capacidade de absorver o clássico e o romântico (que para Garrett quase pode ter a acepção de "moderno") que ele louva em si mesmo.

\section{IV}

Encaminho-me para a conclusão indicando que a síntese que Garrett buscou operar entre o clássico e o romântico não é meramente estética, inclui igualmente os temas que lhe vieram das leituras dos clássicos (gregos e romanos), nomeadamente a defesa da liberdade na esfera política, na religiosa e no campo dos afetos.

Mostrei que na fundação do Conservatório Geral de Arte Dramática (depois Conservatório Real de Lisboa), na redação do REGIMENTO e dos ESTATUTOS, Garrett buscou equilibrar um forte pendor democrático com o respeito às fórmulas monárquicas, que, no seu modo de ver e sentir, estavam na índole, não apenas do povo português, mas do Velho Mundo.

Na constituição da biblioteca do Conservatório, também vimos a abertura de Garrett ao mesclar títulos de procedência bastante variada: clássicos gregos e latinos, autores da literatura portuguesa e outros que escreveram nas línguas europeias modernas.

Em Um auto de Gil Vicente (1838), vimos Garrett encenar a falência do projeto civilizacional de teatro - de defesa da Razão, da Liberdade, das Luzes -, que ele próprio defendeu com enorme determinação como Inspector Geral de Teatros e Vice-Presidente do Conservatório Dramático.

\footnotetext{
${ }^{26}$ Garrett, 2010, pp. 84-85.
} 


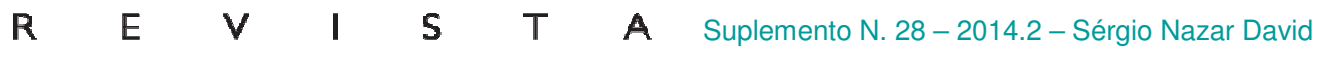

Por fim, quero acrescentar que a síntese clássico / romântico instaura-se também no complexo território das negociações políticas, quando teve de mover-se entre Passos Manuel, "o ilustre e venerando chefe do partido progressista em Portugal, o homem de mais sinceras convicções democráticas, e que mais sinceramente as combina com o respeito e adesão às formas monárquicas" 27 - que o convida para lançar a pedra fundamental de regeneração do teatro português - e Rodrigo da Fonseca Magalhães, que não à toa ficou conhecido com a "Raposa", o defensor do princípio “ordeiro" por excelência.

Passos Manuel pode ter representado para Garrett aquele sopro da liberdade e da democracia. Rodrigo talvez fosse um homem que compreendeu Portugal a fundo e que sabia que o ótimo - sobretudo nos negócios da política - é muitas vezes inimigo do bom.

Clássico aqui talvez tenha sido Passos Manuel, o chefe setembrista, exilado em Santarém. Romântico, com todas as suas contradições e paradoxos, foi certamente Rodrigo, que não quis viver - se evocarmos o célebre discurso do Porto Pireu ${ }^{28}$-, como o famoso louco de Atenas, que supunha serem de sua propriedade todos os navios entrados no Pireu.

Garrett oscilou sempre entre os dois polos: esta terá sido a mais "pasmosa contradição de [sua] dúplice natureza"29.

\section{Referências bibliográficas:}

AMORIM, Francisco Gomes de (1881-1884). Garrett: Memorias Biographicas. Lisboa: Imprensa Nacional, 1881.

GARRETT, Almeida. Discursos parlamentares. In: Obras completas de Almeida Garrett. Ed. de Teófilo Braga. Lisboa: Empreza da Historia de Portugal, vol. XXVI, 1994.

Obras Completas. Porto: Lello \& Irmão, 1963.

. Viagens na minha terra. Ed. de Ofélia Paiva Monteiro. Lisboa: Imprensa NacionalCasa da Moeda, 2010.

Um Auto de Gil Vicente. Porto: Porto Editora, 2011.

Correspondência familiar. Ed. de Sérgio Nazar David. Lisboa: Imprensa NacionalCasa da Moeda, 2012.

\footnotetext{
${ }^{27}$ Garrett, 2010, p. 313.

${ }^{28}$ Garrett, 1904, pp. 63-64, vol. XXVI.

${ }^{29}$ Garrett, 2010, p. 294.
} 
JABOUILLE, Victor. Cultura clássica (leituras e contactos). In: BUESCU, Helena Carvalhão (Coord.). Dicionário do romantismo literário português. Lisboa: Caminho, 1997.

MONTEIRO, Ofélia Paiva (1971). A formação de Almeida Garrett: experiência e criação. Coimbra: Centro de Estudos Românicos, 1971.

A poética de D. Frei Alexandre da Sagrada Família: da língua e do estilo. In: D. Frei Alexandre da Sagrada Família: a sua espiritualidade e a sua poética. Coimbra: Universidade de Coimbra, 1974.

MOURÃO, Paula. Quem é este novo e esdrúxulo poeta, este Sr. João Mínimo?. In: PIMENTEL, Cristina; MOURÃO, Paula. A Literatura Clássica ou os Clássicos na Literatura: uma (re) visão da literatura portuguesa das origens à contemporaneidade. Lisboa: Campo da Comunicação, 2012.

RIBEIRO, José Silvestre. Historia dos estabelecimentos scientificos, literários e artísticos de Portugal nos sucessivos reinados da monarchia. Lisboa: Typographia da Academia Real das Sciencias, tomo VI, 1876.

\section{Garrett and the books: the presence of the classics in the Conservatório Real de Lisboa library}

Garrett's position ahead of Conservatório Real de Lisboa, of Inspecção Geral de Teatros, and also as a member of the committee to build the theatre Dona Maria II, was undeniably in defense of the classics. It is well shown by the list of books that he requested to be collected from the extinct convent libraries for the Conservatory, as well as the list of donations that the Conservatory received. But not only this. The role that Garrett had in the Portuguese theater scene, after returning from Belgium in 1836, has to do with his proximity to Passos Manuel and Rodrigo da Fonseca Magalhães.For the political scene, Garrett was not able to understand any progress without the balance between past and present.Garrett's role in building the Theatre D. Maria II and in the organization of Dramatic Conservatory is consistent with the idea, defended in several pieces of his work, of dialectical relationship between the classical and the romantic.

Key words: Garrett. Conservatório Real de Lisboa. Classics. 